\title{
Effect of post-weld heat treatment on microstructure and mechanical properties of DP800 and DP1200 high-strength steel butt-welded joints using diode laser beam welding
}

\author{
Raghawendra P.S. Sisodia ${ }^{1}$ (D) - Marcell Gáspár ${ }^{1} \cdot$ László Draskóczi $^{2}$ \\ Received: 28 October 2019 / Accepted: 6 February 2020 /Published online: 18 February 2020 \\ (C) The Author(s) 2020
}

\begin{abstract}
Among the available high-strength steels, there is growing demand for dual phase (DP) steels for wide application in the automotive industry owing to their good combination of high strength, ductility and formability. Also, the use of innovative welding technologies like laser beam welding (LBW) has growing importance in the field of high-strength steel because of its excellence in providing high-quality welds, high welding speed, high power density, low heat input, a narrow heat-affected zone and low heat distortions as compared to the conventional gas metal arc welding process. However, the hardening and softening in the heat-affected zone is a major issue when welding high-strength steel, i.e. DP steel grades, greatly affecting the strength, formability and plasticity of the whole-welded joint and thus affecting service performance and reliability. Based on preliminary experiments, the optimal welding condition was a nominal laser power of $1.0 \mathrm{~kW}$ and a welding speed of $8 \mathrm{~mm} / \mathrm{s}$. The aim of this work is to analyse and compare the weld and heat-affected zone characteristics, microstructure and mechanical properties of DP steels with 1-mm thick butt joints of DP800 and DP1200 high-strength steel (HSS) by diode laser beam welding. The effects of post-weld heat treatment (PWHT) on the strengthening of the laser-welded joints were evaluated by microstructural examinations under optical microscope and scanning electron microscope, and mechanical properties were examined by microhardness test, three-point bending tests and tensile tests.
\end{abstract}

Keywords Laser beamwelding $\cdot$ Diode laser $\cdot$ DP steels $\cdot$ Heat-affected zone characterization $\cdot$ Post-weld heat treatment $($ PWHT) $\mathrm{t}_{8 / 5}$ cooling time

\section{Introduction}

Advanced high-strength steels are extensively used in automotive sectors due to their extraordinary combined properties

Recommended for publication by Commission IV - Power Beam Processes

Raghawendra P.S. Sisodia

metraghu@uni-miskolc.hu

Marcell Gáspár

gasparm@uni-miskolc.hu

László Draskóczi

draskoczilaszlo@bubenlaser.com

1 Institute of Materials Science \& Technology, University of Miskolc, Miskolc 3515, Hungary

2 Budai Benefit Ltd., Páger Antal 4, Halásztelek 2314, Hungary of strength, ductility, formability, high-strength to weight ratio and low $\mathrm{CO}_{2}$ emissions [1-5]. Dual phase (DP) steels are a group of low-carbon micro-alloyed steels, and the term 'dual phase' indicates that the steel has two distinct phases, i.e. martensite and ferrite $[6,7]$. In the investigated DP800 and DP1200 steels, the numbers refer to the required minimum guaranteed value of tensile strength in MPa [8]. Martensite is a very hard phase with body-centred tetragonal structure, while ferrite is a relatively soft phase with a body-centred crystal structure [9]. This microstructure with ferritic grain matrix and martensite islands may have considerable amount of bainite depending on the process route and steel composition of hot rolled strips [10]. More importantly, obtaining a martensitic structure in the weld metal strengthens ultrahighstrength steel (UHSS) joints [11]. A common technology for joining these materials is laser welding, and it can be described as a high-productivity welding method suitable for UHSS as well as most automotive applications $[12,13]$. 
Table 1 LBW and PWHT parameters

\begin{tabular}{|c|c|c|c|c|c|c|}
\hline \multirow[t]{2}{*}{ Steel } & \multicolumn{6}{|c|}{ Laser beam welding (LBW) and post-weld heat treatment parameters (PWHT) } \\
\hline & Process & $\begin{array}{l}\text { Laser beam spot } \\
(\mathrm{mm} \times \mathrm{mm})\end{array}$ & $\begin{array}{l}\text { Laser power } \\
\text { (W) }\end{array}$ & $\begin{array}{l}\text { Welding speed } \\
(\mathrm{mm} / \mathrm{s})\end{array}$ & Gas flow rate $(1 / \mathrm{min})$ & Shielding gas \\
\hline \multirow[t]{2}{*}{ DP800/DP1200 } & LBW & $2 \times 2$ & 1000 & 8 & 7 & Ar 4.6 \\
\hline & PWHT & $15 \times 6$ & 275 & 4 & 7 & Ar 4.6 \\
\hline
\end{tabular}

Laser beam welding (LBW) is a high power density welding process with more than $10^{6} \mathrm{~W} / \mathrm{cm}^{2}$, which is about 1000 times higher than in conventional arc welding [14]. Laser beam welding is praised for its technology, which ensures the highest reliability for its intended application while providing the most efficient, highly accurate and versatile process to join DP steels with low weld heat input, narrow weld, a limited heat-affected zone (HAZ), relatively low distortion and good penetration [15-17]. If the welding heat input is low (as in LBW), hardening can occur, indicating that the cold cracking sensitivity [18] and its influence on the HAZ is significantly lower and the microstructure degradation is less than in conventional arc welding technologies $[14,19]$. However, there is a major issue with softening in the HAZ of welded joints with longer cooling time for various grades of DP steels in the critical subzones, which reduces the load bearing capacity of the welded joint.

The main benefits of diode lasers are that the focused area can be enlarged to the whole weld and HAZ. Therefore, the diode laser is a unique technology that provides the opportunity to perform welding and then post-weld heat treatment (PWHT) with a rectangular beam source, which is in many cases the best shape to cover a wider area for surface hardening or tempering. PWHT can significantly improve the fatigue life, the lifetime of the joints, the crack resistance and other mechanical properties (e.g. toughness) [20].

In this paper, the major aim was to analyse microstructural changes and the mechanical properties of two automotive high-strength DP steels (DP800 and DP1200) and the effects of PWHT on the improvement of joint characteristics using diode laser technology. The microstructure, microhardness, strength properties and bending performance were examined to evaluate joint behaviour, including the weld zone and HAZ.

\section{Experimental procedures}

Specimens for welding experiment were cut from a steel sheet into pieces of $300 \mathrm{~mm} \times 150 \mathrm{~mm}$ each for a butt-welded joint (according to EN 15614-11:2002) [11] by means of a CORTINA DS $2600 \mathrm{CNC}$ waterjet cutting machine. Before welding, the edges of the specimens were cleaned with emery paper and acetone to remove surface oxide. The laser welding was done using a diode laser. The welding parameters used in the present study are shown in Table 1.

The Laserline LDL 160-3000 diode laser head was mounted on a Reis SRV 40 robotic arm (Fig. 1a). The working stretch of the robotic arm is $3800 \mathrm{~mm} \times 3800 \mathrm{~mm}$. A schematic diagram of the laser welding set-up is shown in Fig. 1b. The diode laser was characterized by a rectangular laser beam spot size $2 \mathrm{~mm} \times 2 \mathrm{~mm}$ and emitted in a continuous wave at 940 $980 \mathrm{~nm}$, with a maximum output power of $3 \mathrm{~kW}$.

The specimens to be welded were placed on the working table and mounted to a clamping device to protect against distortions, as shown in Fig. 1a. The autogenous laser welding of a butt joint (Fig. 2a) was carried out at a speed of $8 \mathrm{~mm} / \mathrm{s}$ under ultrahigh purity argon (Argon 4.6, 99.996\%) as a shielding gas, with a flow rate of $7 \mathrm{l} / \mathrm{min}$.

Then, the welded joints were subjected to post-weld heat treatment after the samples had cooled down to room
Fig. 1 a Laser head mounted on robot. b LBW experimental set-up
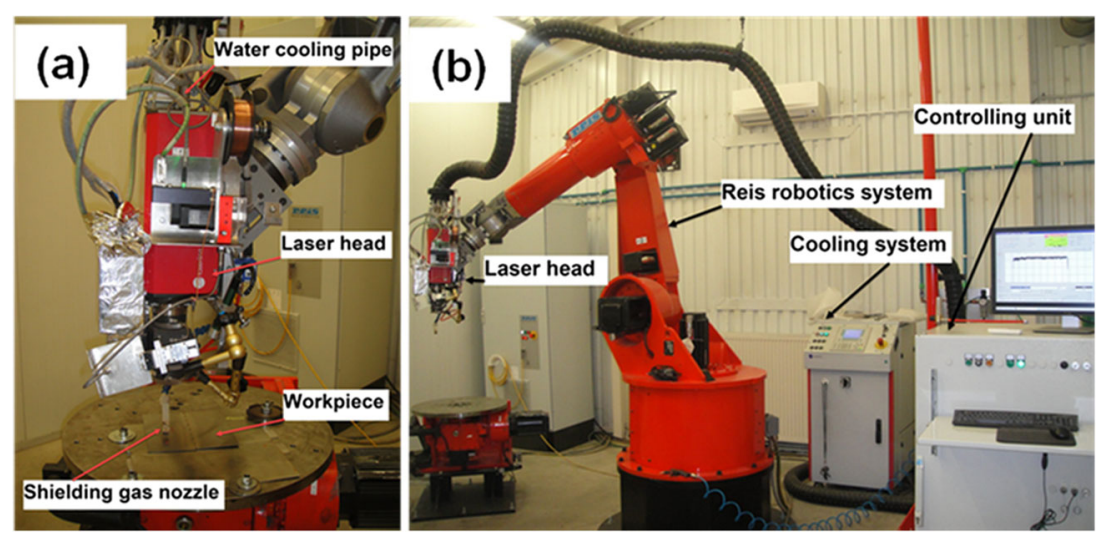
Fig. 2 DP1200. (a) Butt-welded joint (b) LBW and PWHT joints

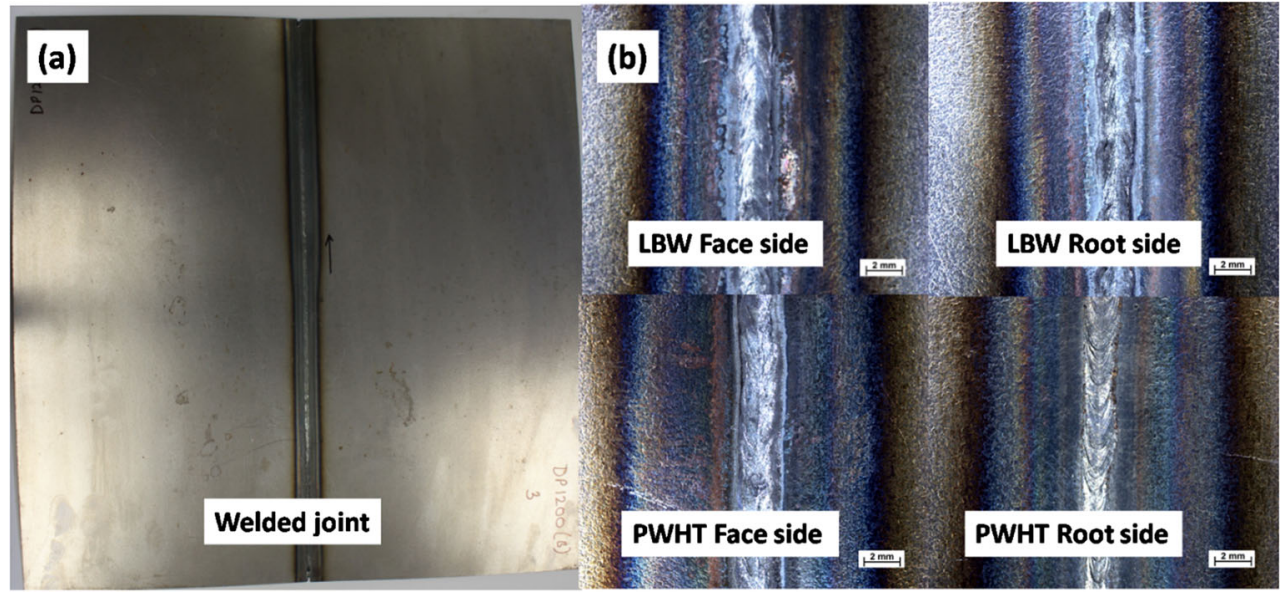

temperature (Fig. 2b) to study the changes in their microstructure and mechanical properties. For post-weld heat treatment, a Laserline LDF 5000-40 diode laser was used, characterized by a rectangular laser beam spot $15 \mathrm{~mm} \times 6 \mathrm{~mm}$ emitted in a continuous wave at 940 to $1060 \mathrm{~nm}$ with a maximum output power of $5 \mathrm{~kW}$. Laser heat treatment was carried out at a speed of $4 \mathrm{~mm} / \mathrm{s}$ in longitudinal direction and an output power of 275 W. The PWHT set-up is shown in Fig. 3.

Laser welding experiments were carried out under various process parameters to obtain full-penetrated welds with good surface quality and cross-section geometry. After welding, the cross section of the joints was cut, polished and finally etched. Microstructure of the welded joints was observed using an optical microscope (OM) and a scanning electron microscope (SEM). The Vickers microhardness test (ISO 9015-2: 2016) was performed on the etched cross sections with a load of $200 \mathrm{~g}$ for a $15-\mathrm{s}$ dwell time. The tensile properties (ISO 4136: 2012) perpendicular to the weld directions were evaluated at room temperature on two samples. A three-point bending test (EN 5173: 2010) was carried out at room temperature on four samples.

\subsection{Materials and compositions}

The material investigated was commercial uncoated coldrolled DP800 and DP1200 steel supplied by Swedish Steel
(SSAB) with a thickness of $1 \mathrm{~mm}$ and the steel sheet cut in the rolling direction. The chemical composition and mechanical properties of both steel grades are given in Tables 2 and 3, respectively; data are taken from material certificates provided by the materials supplier. However, the hardness and ferriteto-martensite ratio were determined by scanning electron microscope in the university laboratory. Regarding the chemical composition, note that both alloys have nearly the same carbon equivalent and there is no significant difference in the chemical composition. Therefore, the higher strength of DP1200 can be attributed to the production technology (cold rolling, intercritical heating) resulting in a higher ferrite-tomartensite ratio.

\subsection{Diode laser}

Although diode laser equipment was originally developed for surface treatments, it can provide a unique possibility to perform the welding and the PWHT with the same heat source. The diode laser head consists of one or more diode stacks and lenses/optics to guide and form the beam. The individual diode laser bars are stacked one on top of the other and form the diode laser stack. In contrast to other laser sources in which a single high-power beam is generated in the laser-active medium, high-performance diode laser systems are based on the combination of many individual bundles of beams. The beam

Fig. 3 a Control display. b Postweld heat treatment (PWHT) experimental set-up

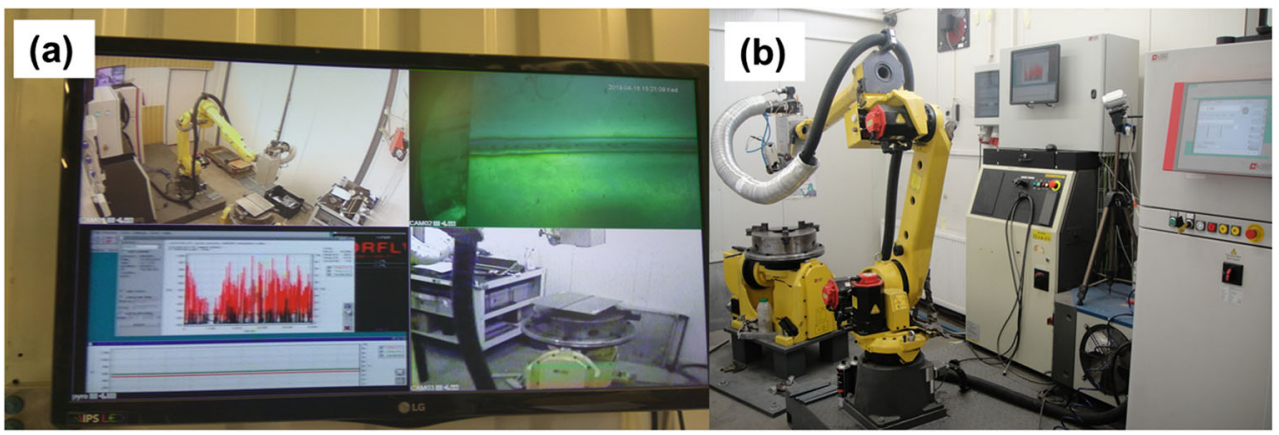


Table 2 Chemical compositions of the investigated base materials (wt.\%)

Steel Chemical compositions of the investigated base materials (wt.\%)

\begin{tabular}{llllllllllllllllllll} 
& $\mathrm{C}$ & $\mathrm{Si}$ & $\mathrm{Mn}$ & $\mathrm{P}$ & $\mathrm{S}$ & $\mathrm{Cr}$ & $\mathrm{Ni}$ & $\mathrm{Mo}$ & $\mathrm{V}$ & $\mathrm{Ti}$ & $\mathrm{Cu}$ & $\mathrm{Al}$ & $\mathrm{Nb}$ & $\mathrm{B}$ & $\mathrm{N}$ & $\mathrm{CEV}$ \\
\hline DP800 & 0.136 & 0.20 & 1.55 & 0.013 & 0.003 & 0.03 & 0.04 & 0.00 & 0.01 & 0.00 & 0.01 & 0.046 & 0.016 & 0.0003 & 0.003 & 0.41 \\
DP1200 & 0.105 & 0.20 & 1.59 & 0.011 & 0.003 & 0.03 & 0.03 & 0.00 & 0.01 & 0.03 & 0.01 & 0.042 & 0.000 & 0.0022 & 0.005 & 0.38 \\
\hline
\end{tabular}

sources themselves are tiny semiconductor diodes which are assembled in a line to form a so-called bar [21]. (Recently multi-kilowatt diode lasers have become available on the market. This type of laser is ideal for surface treatments.) The laser device can be mounted to a robot, allowing the processing of more complex 3D geometries. The beam shape is rectangular, which is in many cases the best shape for heat treating. Since all of the heating energy is brought to the material via absorption [22], the maximum conversion efficiency of transforming input electrical energy into light in diode laser bars is about $59 \%$, which translates into a total electrical efficiency of about $40 \%$ for a high-power diode laser system. This is many times higher than for any other laser type. This high efficiency lowers the operating cost of the system and reduces the carbon footprint of the laser operation. [23].

\subsection{Cooling time}

\subsubsection{Analytical method}

The major parameter for the determination of the material behaviour of steel is the cooling rate; it has a much larger effect than the overheating rate and holding time. For the evolution of the material properties of steel, the $t_{8 / 5}$ time is the major parameter. Transformation of austenite in highstrength steels usually takes place in the temperature interval of approximately 800 to $500{ }^{\circ} \mathrm{C}$, and usually as cooling time in this range increases, the microstructure and therefore crack resistance may change favourably. The final microstructure and the mechanical properties are primarily determined by the cooling circumstances in this temperature range, although the martensitic transformation often finishes under $500{ }^{\circ} \mathrm{C}$. The cooling time of a given point in the weld or HAZ for

Table 3 Mechanical properties of investigated base materials

\begin{tabular}{llllll}
\hline Steel & \multicolumn{4}{l}{ Mechanical properties of investigated base materials } \\
\cline { 2 - 6 } & $\mathrm{R}_{\mathrm{p} 0.2}, \mathrm{MPa}$ & $\mathrm{R}_{\mathrm{m}}, \mathrm{MPa}$ & $\mathrm{A}_{8}, \%$ & $\mathrm{HV} 10$ & $\begin{array}{l}\text { Ferrite-to- } \\
\text { martensite ratio, \% }\end{array}$ \\
\hline DP800 & 585 & 871 & 15.5 & 270 & $55-45$ \\
DP1200 & 1108 & 1289 & 4.5 & 386 & $21-79$ \\
\hline
\end{tabular}

different heat inputs of laser welding can be calculated by means of the equation commonly used in arc welding but adopted for laser beam welding conditions [24, 25]:

$t_{8 / 5}=\left(4300-4.3 \cdot T_{0}\right) \cdot 10^{5} \cdot \frac{k^{2} \cdot E^{2}}{d^{2}} \cdot\left[\left(\frac{1}{500-T_{0}}\right)^{2}-\left(\frac{1}{800-T_{0}}\right)^{2}\right] \cdot F_{2}$

where $E=$ heat input $(\mathrm{kJ} / \mathrm{mm}) ; T_{0}=$ working temperature $\left({ }^{\circ} \mathrm{C}\right)$; $k=$ thermal efficiency; $d=$ material thickness $(\mathrm{mm}) ; F_{2}=$ joint type factor (for butt joint, the value is 0.9 ). The component $E$ of the above equation is originally defined as arc energy in $\mathrm{kJ} /$ $\mathrm{mm}$ (theoretical heat input), but it was replaced by the energy of the laser beam defined as a quotient of the laser power and welding speed: $E=W / v(\mathrm{~kJ} / \mathrm{mm})$. In turn, the thermal efficiency $k$ is given for different arc processes and indicates the amount of heat really transferred into the material. Adopting the $k$ factor for laser welding conditions, it was assumed that the thermal efficiency is directly correlated to the value of laser beam absorption by the material. Thus, in the case of conduction laser welding mode, the laser beam energy is absorbed on the top surface of a joint and a weld pool (socalled Fresnel absorption). The value of the Fresnel absorption for laser radiation on the surface of steel is 0.4 [26], so this value was taken as the thermal efficiency $k$. The value of absorption coefficient depends upon the surface roughness and surface coating, and it can be increased by increasing

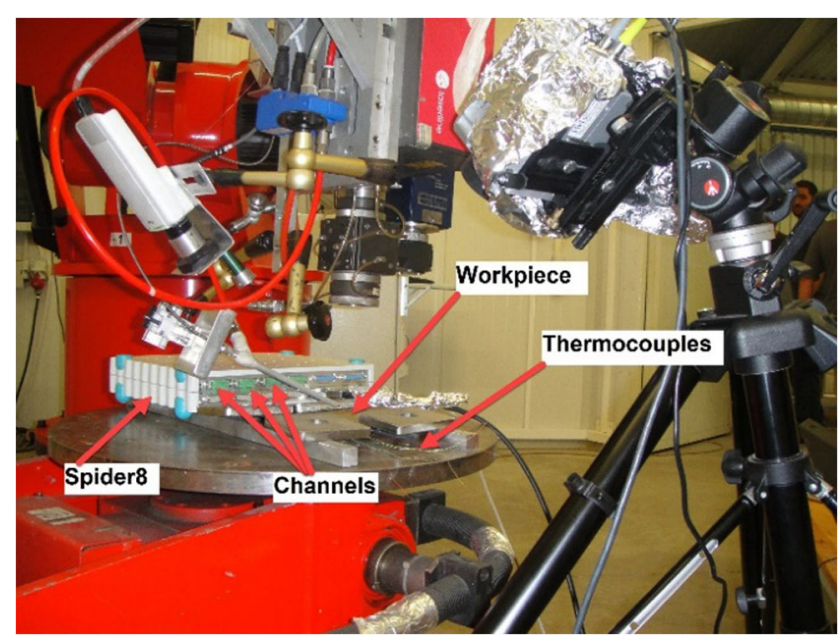

Fig. 4 Experimental set-up of the thermocouples 
Fig. 5 a Schematic diagram of thermocouples arrangement. b Temperature-time curve, thermocouple output (a)

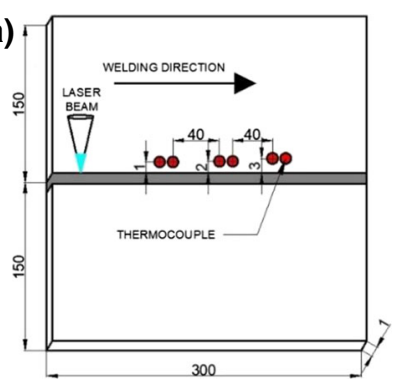

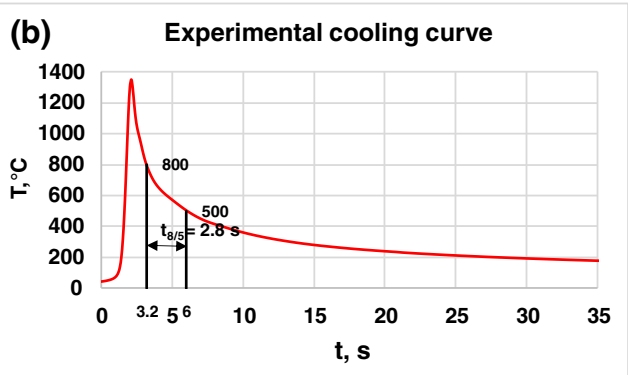

the surface roughness and providing surface coating [27]. The working temperature was assumed to be $20{ }^{\circ} \mathrm{C}$ and the material thickness $d=1 \mathrm{~mm}$. The value of the cooling time between 800 and $500{ }^{\circ} \mathrm{C}$ during laser beam welding of butt joints at heat input $0.125 \mathrm{~kJ} / \mathrm{mm}$ is $2.56 \mathrm{~s}$.

\subsubsection{Experimental method}

The thermal profile in the diode laser beam welding experiments on 1-mm thickness DP800 steel plate was measured. Three sets of K-type thermocouples were welded on the plate along with the butt joint and instrumented with an HBM Spider8 (4 carrier frequency channels) electronic measuring system for electric measurement of temperature profiles. The thermocouples were placed at a distance of $1 \mathrm{~mm}, 2 \mathrm{~mm}$ and $3 \mathrm{~mm}$ from the weld for measuring $t_{8 / 5}$ cooling time. The experimental set-up of the thermocouples for laser beam welding is shown in Fig. 4.

The data (temperature-time curve) from the thermocouples output were recorded at a $25-\mathrm{Hz}$ frequency using CATMAN 3 computer software with the Spider8 device connected to a computer. The schematic diagram of thermocouples arrangement and the measured temperature cycles for a thermocouple at a distance of $1 \mathrm{~mm}$ are shown in Fig. $5 \mathrm{a}$ and b, respectively; peak temperature is $1350^{\circ} \mathrm{C}$, and the $t_{8 / 5}$ cooling time measured from the experimental work is $2.8 \mathrm{~s}$. The other two thermocouples were welded at a distance of $2 \mathrm{~mm}$ and $3 \mathrm{~mm}$ from weld, measuring a peak temperature of $950{ }^{\circ} \mathrm{C}$ and $562{ }^{\circ} \mathrm{C}$, respectively, and the $t_{8 / 5}$ cooling time for the thermocouple placed at $2 \mathrm{~mm}$ is $2.9 \mathrm{~s}$.

From both methods (analytical and experimental), it can be concluded that $t_{8 / 5}$ cooling time is approximately the same which is conforming the result.

\section{Results}

\subsection{Tensile test}

Butt-welded joints were used to make tensile tests specimens. The specimen was milled from the welded sheets, and all transverse tensile tests were executed according to ISO 4136:2012 standard with MTS 810.23-250 kN electric hydraulic universal testing equipment. The specimens of both
Fig. 6 Tensile test fractured specimens; DP800 a LBW and b PWHT; DP1200 c LBW and d PWHT
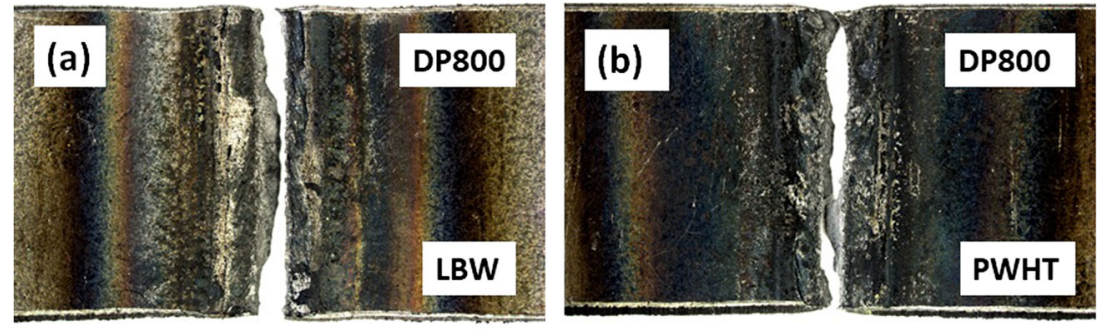

$2 \mathrm{~mm}$
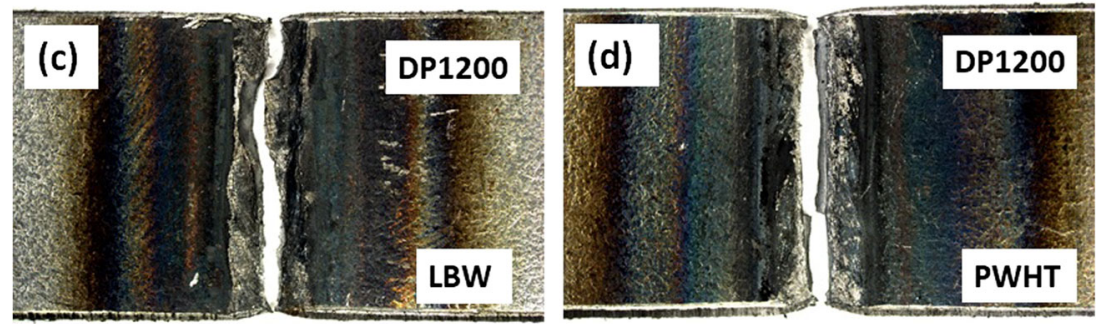

$2 \mathrm{~mm}$ 
Table 4 Tensile properties of LBW-welded joints and PWHT-welded joints

\begin{tabular}{|c|c|c|c|c|c|c|c|}
\hline \multirow[t]{2}{*}{ Steel } & \multirow[b]{2}{*}{ Process } & \multicolumn{6}{|c|}{ Tensile results of laser-welded joints and PWHT } \\
\hline & & No. & $\begin{array}{l}\text { Laser power } \\
\text { (W) }\end{array}$ & $\begin{array}{l}\text { Speed } \\
(\mathrm{mm} / \\
\mathrm{s})\end{array}$ & $\begin{array}{l}\text { Force } \\
(\mathrm{N})\end{array}$ & $\begin{array}{l}\text { Tensile strength } \\
\text { (MPa) }\end{array}$ & Fracture location \\
\hline \multirow[t]{4}{*}{ DP800 } & LBW & 1 & 1000 & 8 & 10,133 & 780 & Weld metal \\
\hline & LBW & 2 & 1000 & 8 & 10,386 & 793 & Weld metal \\
\hline & PWHT & 3 & 275 & 4 & 8774 & 768 & Weld metal \\
\hline & PWHT & 4 & 275 & 4 & 9011 & 788 & Weld metal \\
\hline \multirow[t]{4}{*}{ DP1200 } & LBW & 5 & 1000 & 8 & 8525 & 772 & Weld metal \\
\hline & LBW & 6 & 1000 & 8 & 8885 & 812 & Weld metal \\
\hline & PWHT & 7 & 275 & 4 & 8622 & 796 & Weld metal \\
\hline & PWHT & 8 & 275 & 4 & 8472 & 785 & Weld metal \\
\hline
\end{tabular}

LBW and PWHT joints were fractured along the weld centreline of the joint which are shown in Fig. $6 a$ and $b$ for DP800 and Fig. 6c and d for DP1200, respectively.

Tensile properties of the joints under different welding parameters are shown in Table 4.

With the given welding parameters, the fracture is initiated in the weld zone, which indicates the softening of this part. Based on the data presented in Table 4, we can conclude that the application of the higher strength base material (DP1200) did not result the higher strength of the welded joint with this heat input. PWHT had no significant effect in terms of the tensile strength results since the measured values were just slightly lower (sometimes even higher) compared to the simple LBW tests.

\subsection{Hardness test}

The microhardness distributions of joints for LBW and PWHT were obtained using a Mitutoyo microhardness tester with HV0.2 load and with a 15-s dwell time, and the test was performed before bending test on a simple macro test specimen manufactured from the transversal cross section of the welded joint. The micro indentations of different subregions of a joint for DP800 and DP1200 are shown in Fig. 7a and b, respectively.

For DP800, the fusion zone (FZ) has nearly the same hardness as the base material (BM), and most of the HAZ has a higher hardness (around 400 HV0.2), which shows a gradual decrease from the fusion line to base metals. PWHT helps in the reduction of hardness peaks, bringing values closer to the base metal, which can be beneficial in terms of cold cracking sensitivity.

For DP1200, we can observe from the graph that the weld hardness is lower than that of the base metal and also softening occurs in the HAZ. Regarding the hardness peaks, similar values were measured compared to DP800, which can be explained by the same heat input and nearly identical chemical compositions. PWHT reduces the hardness peaks in the HAZ without changing the total strength of the welded joint.

\subsection{Bending test}

The bending test was carried out on LBW- and PWHT-welded joints by ZD20 hydraulic testing equipment to identify the tendency to crack during deformation due to the presence of weld imperfections in the area of the face and root side of the
Fig. 7 The microhardness distribution of the LBW and PWHT joints. a DP800. b DP1200
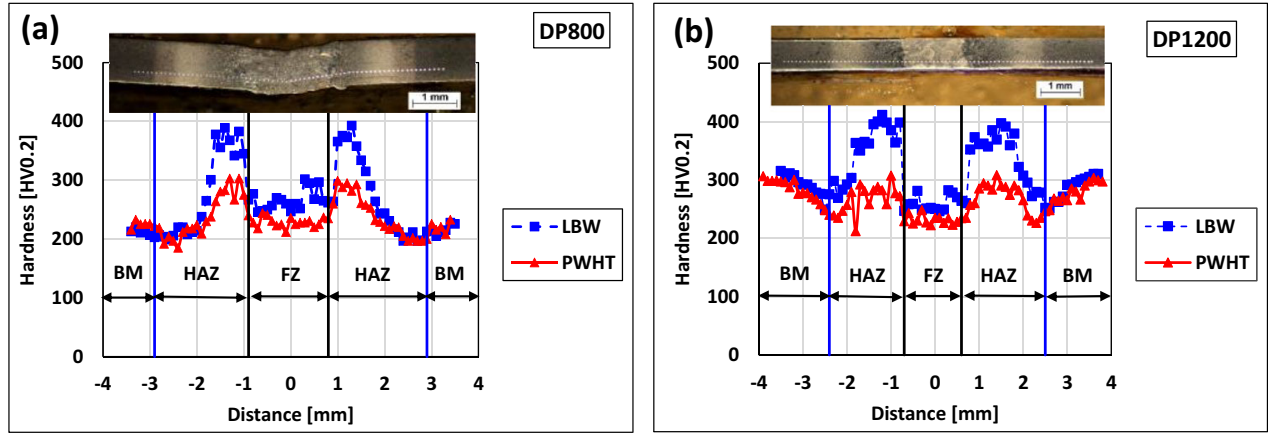


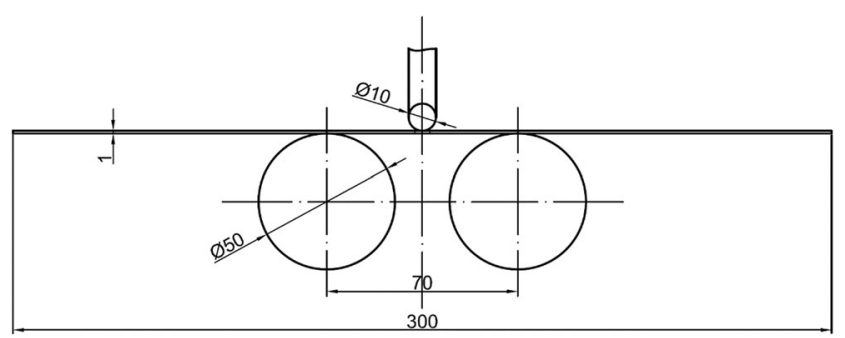

Fig. 8 Schematic diagram of the three-point bending test set-up

weld. A three-point bend test (EN 5173: 2010) was carried out on the face side and root side of the joints to evaluate the bending property of joints, as shown in Fig. 8. The test specimen is a rectangular plate of $300-\mathrm{mm}$ length, width of $20 \mathrm{~mm}$ and thickness of $1 \mathrm{~mm}$. The indenter diameter is $10 \mathrm{~mm}$, fixed support roller diameter is $50 \mathrm{~mm}$ and the support span (distance between the rollers) is $70 \mathrm{~mm}$.

In nearly all cases, results of the bending test for the face side or root side were perfect, without cracks, which indicates good plastic properties of the welded joint. The one exception was root side bending of LBW joint DP800 steel (2RS), where the metal is weakened by fusion defect and finally bending fracture occurred. In sample number 7FS, a larger bending angle $(\alpha)$ was achieved because of better plasticity in the zone. The results of the bending test are shown in Table 5.

The bended specimen of the laser beam welded, and postweld heat treated joint of DP800 and DP1200 are shown in Fig. 9a and $\mathrm{b}$.

\subsection{Microscopic test}

The microstructure of the laser-welded and post-weld heat treated joints of DP800 and DP1200 steels was observed by OM (Figs. 10 and 11) and SEM (Figs. 12 and 13). The microstructural analysis was carried using the optical microscope Axio Observer D1m (Zeiss) inverted microscope and a Zeiss Evo MA10 scanning electron microscope. As illustrated in Fig. 10a, the HAZ can be divided into subregions: coarsegrained HAZ (CGHAZ), fine-grained HAZ (FGHAZ) and intercritical HAZ (ICHAZ).

In the optical micrographs of the base materials, we can see the ferrite parts in white, and in the SEM images, they are more deeply etched than the martensite grains. Regarding CGHAZ, we can conclude that the generally a lathe-like martensitic microstructure forms which is in correlation with measured hardness peaks. In some parts of FGHAZ, smaller grain size is measured compared to the base metal. In ICHAZ, the ferrite-to-martensite ratio of the base material is modified due to the welding heat input as a function of the peak temperature. This could be the reason for softening in DP1200. When PWHT is applied, tempered martensitic parts can be identified in CGHAZ and in the martensitic grains of ICHAZ.

\section{Conclusion}

Autogenous laser welding experiments were carried out under various process parameters to obtain full-penetrated welds with the good surface quality and cross-section geometry. High-strength steel (DP800 and DP1200) sheets of 1-mm thickness were welded using a diode laser (LBW, power = $1000 \mathrm{~W}$; speed $=8 \mathrm{~mm} / \mathrm{s}$, gas flow rate $=71 / \mathrm{min})$. The diode laser can be ideal in terms of post-weld heat treatment (PWHT, power $=275 \mathrm{~W}$, speed $=4 \mathrm{~mm} / \mathrm{s}$, gas flow rate $=7 \mathrm{l} / \mathrm{min}$ ) since both the welding and the heat treating of the weld and HAZ can be performed with one heat source by adjusting the focus area.

The strength of the welded joints is critical due to the weld softening originating from autogenous welding, a

Table 5 Bending properties of LBW-welded joint and PWHT-welded joint

\begin{tabular}{|c|c|c|c|c|c|c|}
\hline \multirow[t]{2}{*}{ Steel } & \multicolumn{6}{|c|}{ Bending tests of laser-welded joints and PWHT } \\
\hline & Process & Sample no. & $\begin{array}{l}\text { Laser power } \\
\text { (W) }\end{array}$ & $\begin{array}{l}\text { Speed } \\
(\mathrm{mm} / \mathrm{s})\end{array}$ & Bending angle $\left(^{\circ}\right)$ & Final result \\
\hline \multirow[t]{4}{*}{ DP800 } & LBW & 1FS (face side) & 1000 & 8 & 135 & No cracks \\
\hline & LBW & 2RS (root side) & 1000 & 8 & 149 & $\begin{array}{l}\text { Minor crack in } \\
\text { weld zone }\end{array}$ \\
\hline & PWHT & 3FS (face side) & 275 & 4 & 140 & No cracks \\
\hline & PWHT & 4RS (root side) & 275 & 4 & 137 & No cracks \\
\hline \multirow[t]{4}{*}{ DP1200 } & LBW & 5FS (face side) & 1000 & 8 & 136 & No cracks \\
\hline & LBW & 6RS (root side) & 1000 & 8 & 136 & No cracks \\
\hline & PWHT & 7FS (face side) & 275 & 4 & 116 & No cracks \\
\hline & PWHT & 8RS (root side) & 275 & 4 & 123 & No cracks \\
\hline
\end{tabular}


Fig. 9 Bended specimen; upper (LBW) and lower (PWHT). a DP800. b DP1200
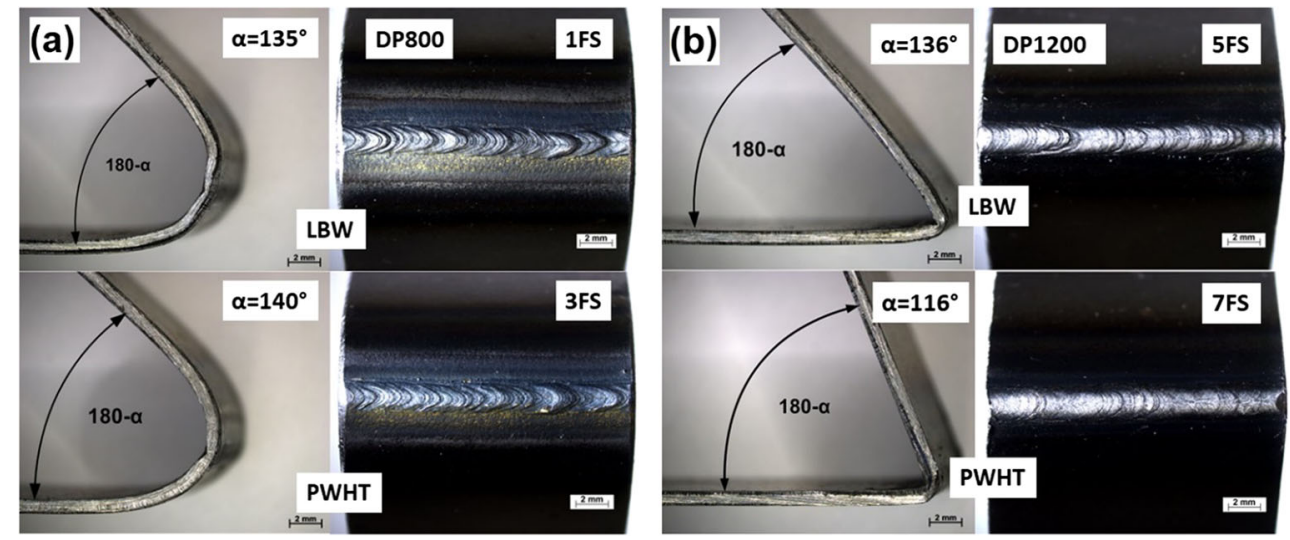

relatively high heat input within LBW technologies and the low amount of alloying (especially carbon content) elements of the base material.

We observed that cooling time obtained by the analytical method is $2.56 \mathrm{~s}$, which is quite close to the measured value of $2.8 \mathrm{~s}$ for $t_{8 / 5}$ cooling time. We can conclude that the analytical result conforms to the experimental result and the method used for experiments offers a new path for further application in the laser beam welding process to determine thermal cycle and $t_{8 / 5}$ cooling time for further detailed research purposes.

With the application of PWHT, hardness peaks in the HAZ (CGHAZ and FGHAZ) were significantly reduced in both materials, which can be beneficial in terms of the cold cracking sensitivity. Although in the present experimental work, where sheets were simply welded in PA position, cracks were not identified in the weld zone (FZ) or HAZ, but in real-welded structures, the hardness peaks and the high residual stress can cause cold cracking if some hydrogen source occurs on the joined surfaces. These tests were done on plate, not in a welded structure. In DP800, PWHT reduces the hardness peaks in the HAZ without significantly changing the total strength of the welded joint. However, there is a slight strength/ hardness reduction in the FZ as well.

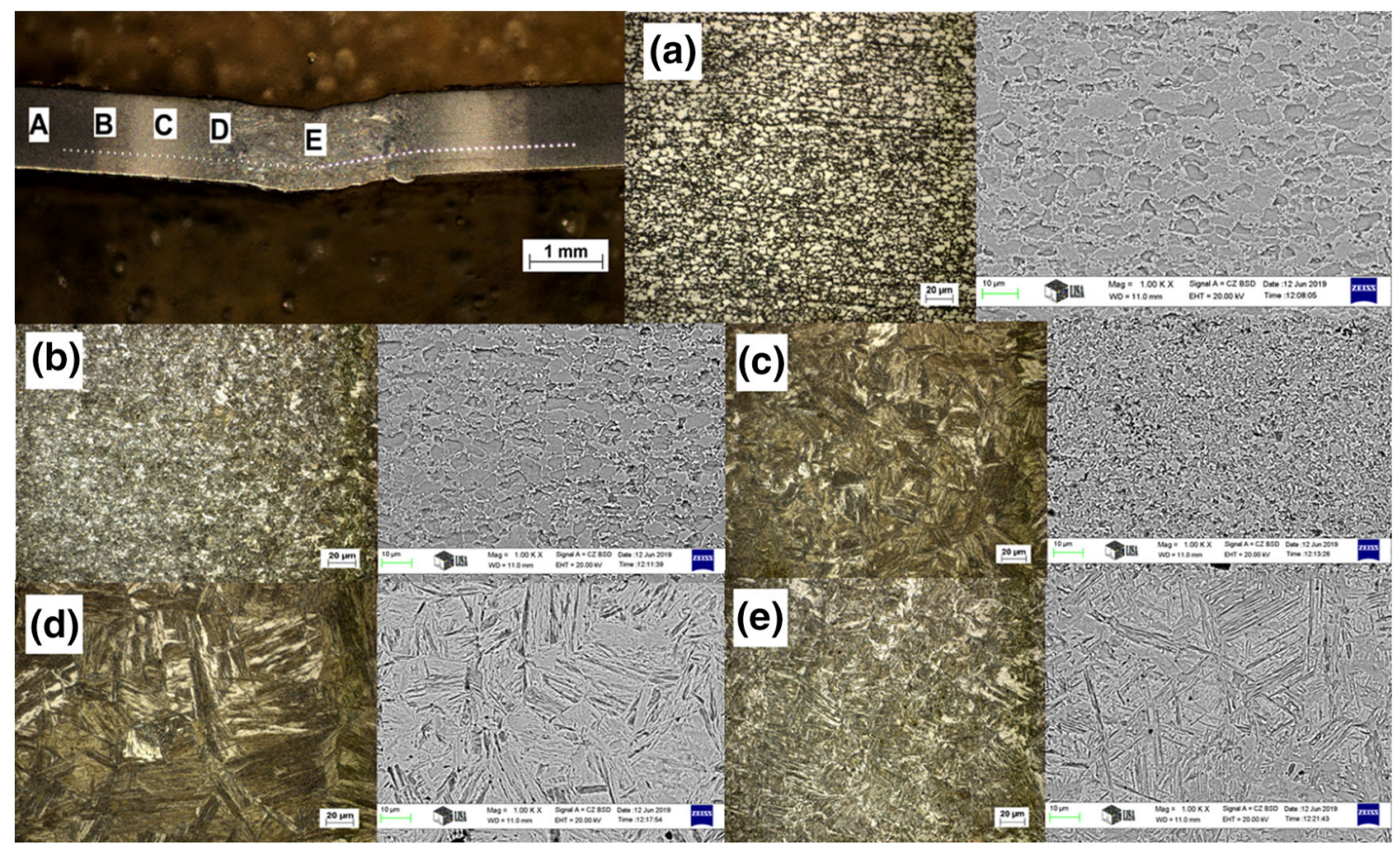

Fig. $10 \mathrm{OM}$ and SEM micrographs of different microstructures in different subzones of the LBW-welded joint of DP800 steel. a Base material. b ICHAZ. c FGHAZ. d CGHAZ. e Weld zone 


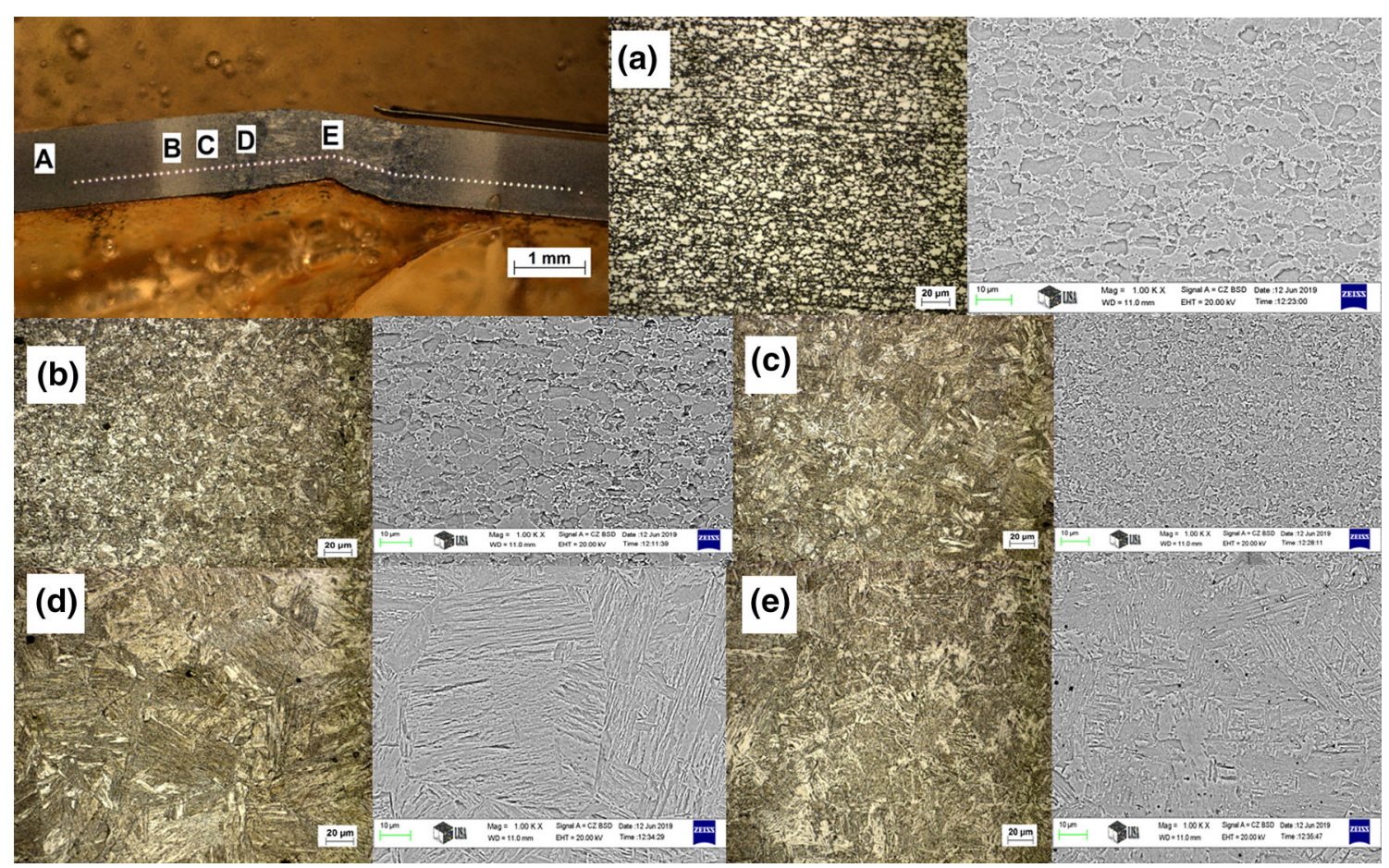

Fig. 11 OM and SEM micrographs of different microstructures in different subzones of the PWHT LBW-welded joint of DP800 steel. a Base material. b ICHAZ. c FGHAZ. d CGHAZ. e Weld zone

The strength and hardness in the FZ could be compensated by the application of a proper filler material which will not lose strength after PWHT. In the planned continuation of the present research work, the welded joints will be prepared by the utilization of filler material and PWHT to identify which combination can be beneficial in terms of avoidance of weld softening and HAZ hardening.

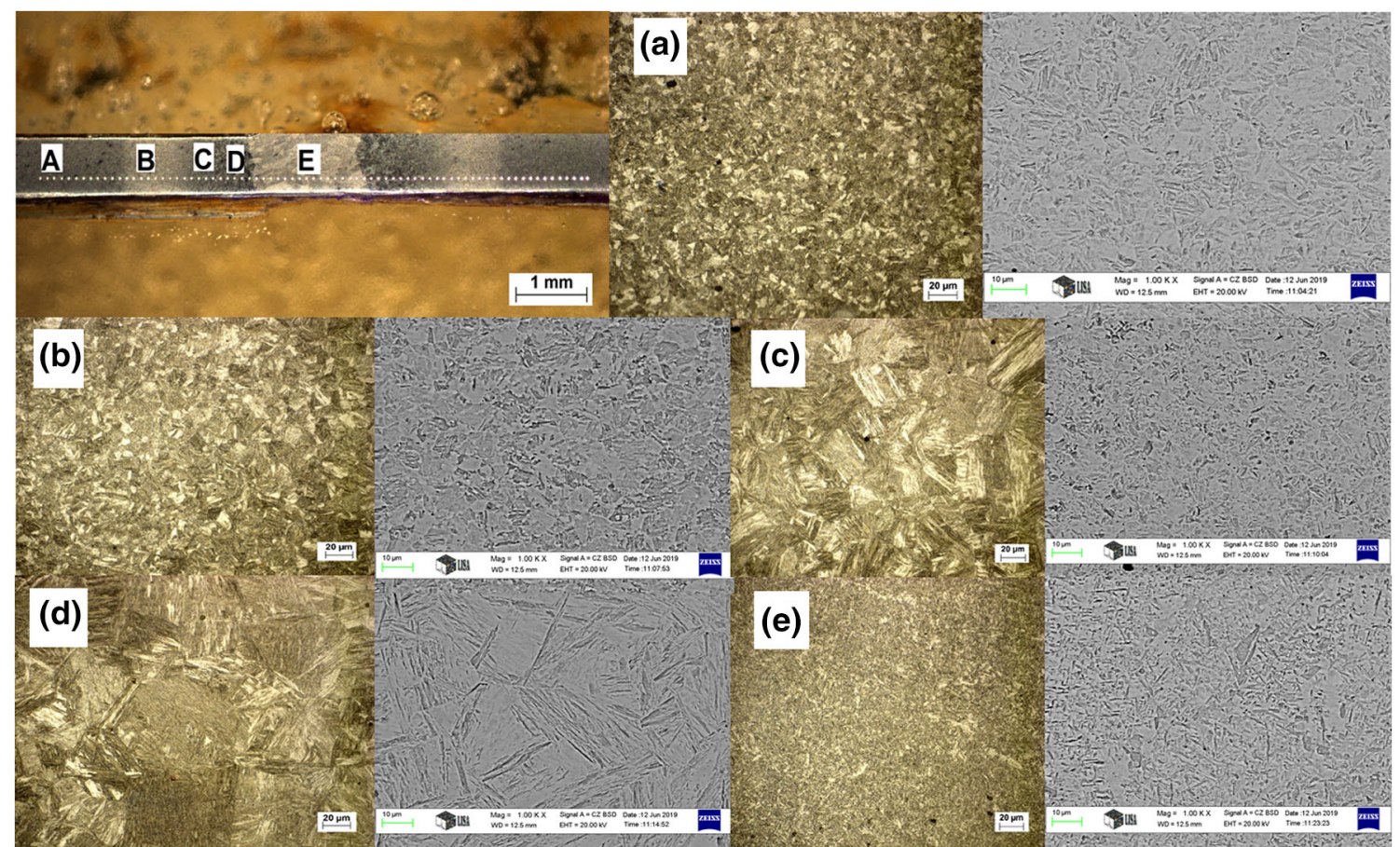

Fig. $12 \mathrm{OM}$ and SEM micrographs of different microstructures in different subzones of the LBW-welded joint of DP1200 steel. a Base material. $\mathbf{b}$ ICHAZ. c FGHAZ. d CGHAZ. e Weld zone 


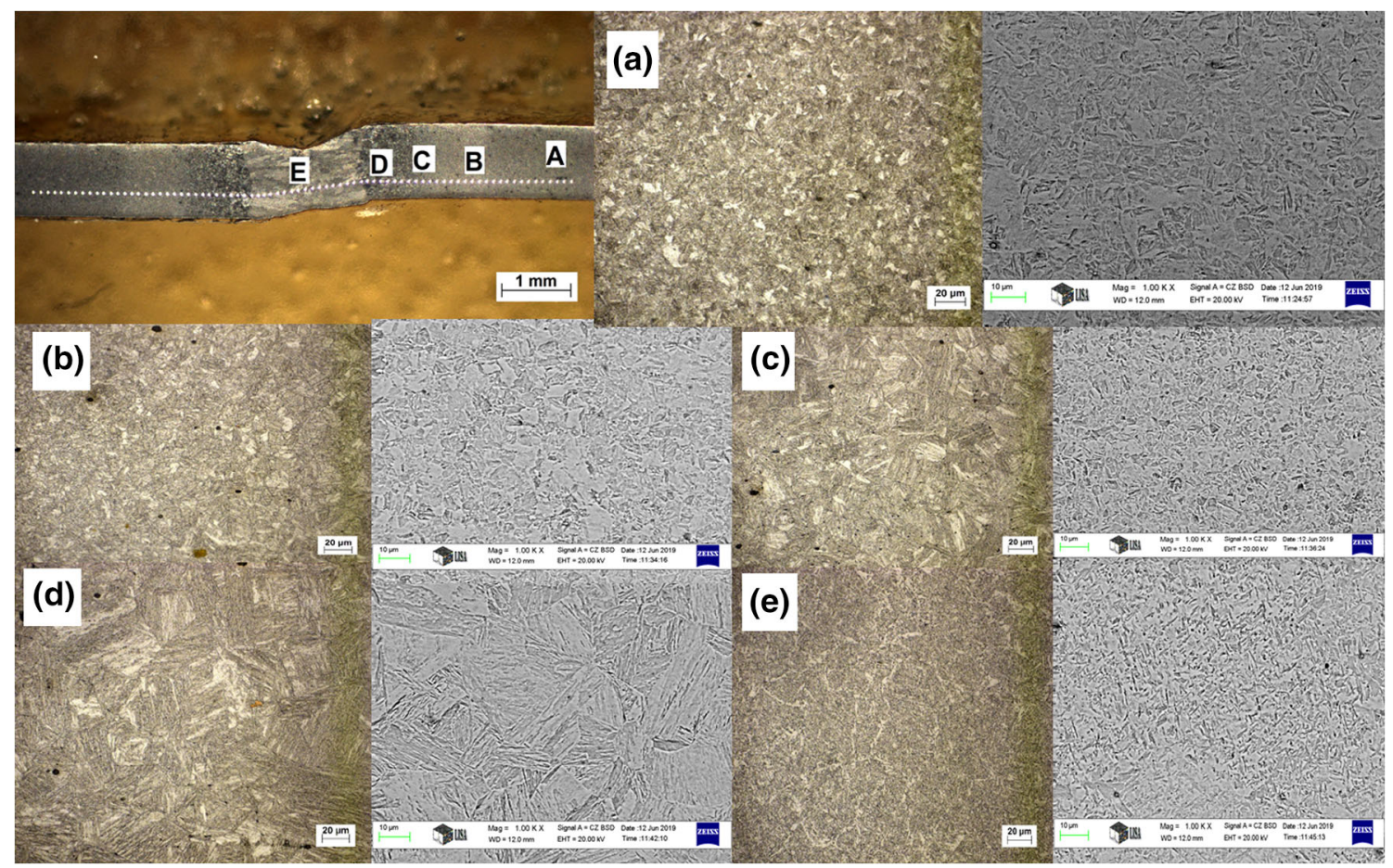

Fig. $13 \mathrm{OM}$ and SEM micrographs of the different microstructures in different subzones of the PWHT LBW-welded joint of DP1200 steel. a Base material. b ICHAZ. c FGHAZ. d CGHAZ. e Weld zone

\begin{abstract}
Acknowledgements The authors also wish to express their deep appreciation to Budai Benefit Ltd., Budapest, Hungary, for their generous cooperation in the production of the laser-welded joints used in this research. The authors are grateful to the Institute of Physical Metallurgy, Metalforming and Nanotechnology at the University of Miskolc for ensuring the scanning electron microscope for the microstructure examinations.
\end{abstract}

Funding information Open access funding provided by University of Miskolc (ME). This research was supported by the European Union and the Hungarian State, co-financed by the European Regional Development Fund in the framework of the GINOP-2.3.4-15-201600004 project, aimed to promote the cooperation between the higher education and the industry.

Open Access This article is licensed under a Creative Commons Attribution 4.0 International License, which permits use, sharing, adaptation, distribution and reproduction in any medium or format, as long as you give appropriate credit to the original author(s) and the source, provide a link to the Creative Commons licence, and indicate if changes were made. The images or other third party material in this article are included in the article's Creative Commons licence, unless indicated otherwise in a credit line to the material. If material is not included in the article's Creative Commons licence and your intended use is not permitted by statutory regulation or exceeds the permitted use, you will need to obtain permission directly from the copyright holder. To view a copy of this licence, visit http://creativecommons.org/licenses/by/4.0/.

\section{References}

1. Eshraghi M, Mark AT,Zaeem MA, Felicelli SD (2013) A parametric study of resistance spot welding of a dual-phase steel using finite element analysis. The 8th Pacific rim international congress on advanced materials and processing, (TMS) the minerals, Metals \& Materials Society, p.3073-3080

2. Wrozyna A, Pernach M, Kuziak R, Pietrzyk M (2016) Experimental and numerical simulations of phase transformations occurring during continuous annealing of DP steel strips. J Mater Eng Perform 25(4):1481-1491. https://doi.org/10.1007/s11665016-1907-9

3. Varbai B, Timothy P, Kornél M (2018) Development and comparison of quantitative phase analysis for duplex stainless-steel weld. Period Polytech-Mech Eng 62:247-253

4. Górka J, Ozgowicz A (2018) Structure and properties of laserbeam-welded joints of low-alloy high-strength steel Docol 1200M with a martensitic structure. Mater Technol 52:189-193

5. Luo C, Cao Y, Zhao Y, Zhao L, Shan J (2018) Fiber laser welding of 1700-MPa, ultra high-strength steel. Weld Res Weld J 97:214-228. https://doi.org/10.29391/2018.97.019

6. Santillan EA, Nayak SS, Xia MS, Zhou Y (2012) Microstructure, hardness and tensile properties of fusion zone in laser welding of advanced high strength steels. Can Metall Q 51(3):328-335. https:// doi.org/10.1179/1879139512Y.0000000002

7. Davies R (1978) Influence of martensite composition and content on the properties of dual phase steels. Metall Trans A 9A(5):671679

8. Dobosy A, Lukács J (2017) The effect of the filler material choice on the high cycle fatigue resistance of high strength steel welded joints. Mater Sci Forum 885:111-116

9. Zhang J, Khan A, Olanrewaju AO, Zhou N, Chen D (2015) Analysis of microstructural changes in the heat-affected zone and fusion zone of a fiber laser welded DP980 steel. The Minerals, Metals \& Materials Society and ASM International 46B:16381646. https://doi.org/10.1007/s11663-014-0283-9

10. Brand M, Siegele D (2007) Numerical simulation of distortion and residual stresses of dual phase steels weldments. Weld World 51(9/10):56-62 
11. Gu Z, Yu S, Han L (2012) Influence of welding speed on microstructures and properties of ultra-high strength steel sheets in laser welding. ISIJ Int 52(3):483-487. https://doi.org/10.2355/ isijinternational.52.483

12. Kim YC, Hirohata M, Inose K (2012) Effects of phase transformation on distortion and residual stress generated by laser beam welding on high-strength steel. Weld World 56:64-70. https://doi. org/10.1007/BF03321336

13. Fahlström K, Andersson O, Todal U, Melander A (2015) Minimization of distortions during laser welding of ultra high strength steel. J Laser Appl 27:S29011-1-8. https://doi.org/10. 2351/1.4906468

14. Nemeček S, Muzík T, Mísek M (2012) Differences between laser and arc welding of HSS steels. Phys Procedia 39:67-74. https://doi. org/10.1016/j.phpro.2012.10.015

15. Tuz L (2018) Evaluation of microstructure and selected mechanical properties of laser beam welded S690QL high-strength steel. Adv Mater Sci 18(57). https://doi.org/10.1515/adms-2017-0039

16. Sumi OK, Yasuda K (2015) Effect of chemical composition on microstructure and mechanical properties of laser weld metal of high-tensile-strength steel. Weld World 59:173-178. https://doi. org/10.1007/s40194-014-0191-2

17. Oyyaravelu R, Kuppan P, Arivazhagan N (2016) Metallurgical and mechanical properties of laser welded high strength low alloy steel. J Adv Res 7(3):463-472. https://doi.org/10.1016/j.jare.2016.03. 005

18. Prém L, Bézi Z, Balogh A (2017) Development of complex spotwelding technologies for automotive DP steels with FEM support. Springer International Publishing, Lecture Notes Mechan Eng. https://doi.org/10.1007/978-3-319-51189-4_36
19. Fahlstrom K, Larsson J (2013) Laser welding of 1900 MPa boron steel. NOLAMP14, Gothenburg

20. Gáspár M, Sisodia R (2018) Improving the HAZ toughness of Q+T high strength steels by post weld heat treatment. IOP Conf Ser Mater Sci Eng 426. https://doi.org/10.1088/1757-899X/426/1/ 012012

21. LaserLine GmbH, Germany, Manual Diode laser, LDM 4000-100

22. Pantsar H, Kujanpää V (2002) The absorption of a diode laser beam in laser surface hardening of a low alloy steel. Laser Instit Am 185. https://doi.org/10.2351/1.5065721

23. Parker K, Welding with high power diode lasers coherent, www. Coherent.com. Accessed 20 June 2019

24. Górka J (2014) Analysis of simulated welding thermal cycles S700MC using a thermal imaging camera. Adv Mat Res ISI Proceedings 837:375-380

25. Lisiecki A (2014) Welding of thermomechanically rolled fine-grain steel by different types of lasers. Arch Metall Mater 59(4):16251631. https://doi.org/10.2478/amm-2014-0276

26. Stanciu EM, Dumitru GM, Păvălache AC, Iacobescu G (2012) Laser welding parameters influence on the geometrical aspect of the melted zone in stainless steel. UPB Scientific Bulletin, Series D: Mechanical Engineering 74(3):179-186

27. Schuöcker D (1998) Handbook of the EuroLaser academy, vol 2. Chapman \& Hall, London

Publisher's note Springer Nature remains neutral with regard to jurisdictional claims in published maps and institutional affiliations. 